\title{
Construction and performance of the Karkheh dam complementary cut-off wall: an innovative engineering solution
}

\author{
Mohammad Heidarzadeh $^{1}$ (D) Ali A. Mirghasemi ${ }^{2} \cdot$ Habib Niroomand $^{3} \cdot$ Faramarz Eslamin $^{3}$
}

Received: 11 June 2018 / Revised: 19 September 2018 / Accepted: 29 October 2018 / Published online: 20 November 2018

(c) The Author(s) 2018

\begin{abstract}
Construction of a dam cut-off wall is one of the most challenging tasks in dam engineering given the deep excavations involved and the complex interactions between stiff cut-off walls and soft surrounding soils. Here, we present innovative solutions for the development of the Karkheh dam's complementary cut-off wall in southwest Iran which is among the largest structures of this type worldwide with a maximum depth of $115 \mathrm{~m}$. Due to excessive water seepage and high hydraulic gradient following the reservoir impoundment, additional measures were considered among which was the extension of the existing cut-off wall. The main goal was to decrease the hydraulic gradient of the seepage through the dam foundation. The construction of this new wall, which is called as the complementary wall here, was associated with a number of technical challenges among which were: the connection between the new and old walls; trenching and placing of plastic concrete wall through different dam body zones; and slurry loss during trenching through the dam body zones. The complementary wall was constructed successfully producing invaluable engineering experiences including: design of a U-shaped panel as the connecting panel; design of a new method for grouting through uniformly distributed filter/drain materials; and adding cement-based grouts to the cut-off wall panels to prevent slurry loss. The complementary wall helped to decrease both total seepage and the hydraulic gradient; for instance, in the right abutment, total seepage was cut for $25 \%$ and the hydraulic gradient was reduced from 0.2 to 0.095 .
\end{abstract}

Keywords Earth dam $\cdot$ Water tightening system $\cdot$ Cut-off wall $\cdot$ Plastic concrete $\cdot$ BC-40 trench-cutter

\section{Introduction and geological background}

Water sealing of the foundations of large dam projects are usually archived by a number of ways including plastic concrete cut-off walls [1,2], multiple-row grouting curtains [3,

Mohammad Heidarzadeh

mohammad.heidarzadeh@brunel.ac.uk

Ali A. Mirghasemi

aghasemi@ut.ac.ir

Habib Niroomand

hn_sahand@yahoo.com

Faramarz Eslamin

faramarzeslamian@gmail.com

1 Department of Civil and Environmental Engineering, Brunel University London, Uxbridge UB8 3PH, UK

2 School of Civil Engineering, College of Engineering, University of Tehran, Tehran, Iran

3 Mahab International Consulting Engineering Company, Tehran, Iran
4], and soil-bentonite slurry trench cut-off walls [5]. Among these methods, application of plastic concrete cut-off wall in a project requires sophisticated geotechnical modeling because the stiffness/elasticity of the plastic concrete wall needs to be consistent with that of the surrounding soil. In addition, this solution demands high-technology trench-cutting machines capable of trenching up to depths of around $100 \mathrm{~m}$ or beyond. Excavation of 100-m deep trenches and placing of plastic concrete diaphragm walls as well as the associated complex computer modeling makes the choice of plastic concrete cut-off wall an expensive and challenging choice in dam engineering. However, such a choice is sometimes unavoidable; especially when the engineer is faced with a highly permeable foundation in a project with a giant reservoir water volume whose failure may endanger the lives of millions of downstream people. This was the case in the Karkheh dam/reservoir project in southwest Iran in 1995 [6-9].

With a reservoir water capacity of about 7400 million cubic meters (MCM) at the maximum water level, Karkheh 
storage dam is the largest dam in Iran. Karkheh project is located on the Karkheh river, the third largest in Iran in terms of flow discharge, in southwest of Iran. The dam is an earth core rock-fill dam with a height of $127 \mathrm{~m}$, a length of $3030 \mathrm{~m}$ and a normal water level of $220 \mathrm{~m}$ above the sea level (masl) (Fig. 1). The project includes the embankment placed across the Karkheh River, a hydroelectric power plant (HPP) with a total capacity of 400 megawatt (MW) at the left abutment and a gated chute-type spillway with a width of $110 \mathrm{~m}$ and length of $955 \mathrm{~m}$ located at the right abutment (Fig. 1).

Regarding the geological condition of the dam site, the dam is placed on poorly/fairly permeable conglomerate beds which are moderately cemented. At the design stage, different methods such as Lugeon and pumping tests were applied to estimate permeability of the conglomerate. In total, 823 Lugeon tests were performed at different locations and down to different geological layers of the dam foundation. In addition, pumping tests were carried out in two conglomerate aquifers below the riverbed. The other methods used for permeability analyses were the data obtained from construction dewatering systems and the data from seepage back-analysis. Due to the complexity of the conglomerate formation, the measured permeability varied in a broad range of about two orders of magnitude. The lowest values for permeability were resulted from the Lugeon tests while pumping test showed higher permeability values. Therefore, state-of-the-art methods for permeability analyses resulted in large uncertainties for permeability values. Furthermore, most part of the dam foundation was placed above the natural ground water level, and therefore, reliable large-scale hydrogeological tests were not possible.

Under such conditions, an accurate and reliable prediction of the permeability values could not have been achieved. Therefore, it was planned to install a comprehensive monitoring system for the dam project [10] and to slowly fill the dam's reservoir. Appropriate remedial works were taken as responses to the observed excessive seepage, high hydraulic gradients and other dam-safety problems detected by the monitoring systems [11]. The permeability of conglomerate was continuously monitored during the dam construction and first reservoir filling. Based on these comprehensive investigations, the average permeability of the conglomerate was estimated in the relatively wide range of (4-9) $\times$ $10^{-4} \mathrm{~m} / \mathrm{s}$ [8]. Such high permeability coefficient is due to the presence of discontinuity zones and open framework gravels within the conglomerate layers. Karkheh's conglomerate foundation includes impervious horizontal mudstone layers each having a thickness of 3 to $9 \mathrm{~m}$ (Fig. 2). The permeability of the mudstone layers, which are bedded almost horizontally, is in the range of $10^{-7}-10^{-10} \mathrm{~m} / \mathrm{s}$ (Fig. 2). Geotechnical investigations revealed that these layers are continuous

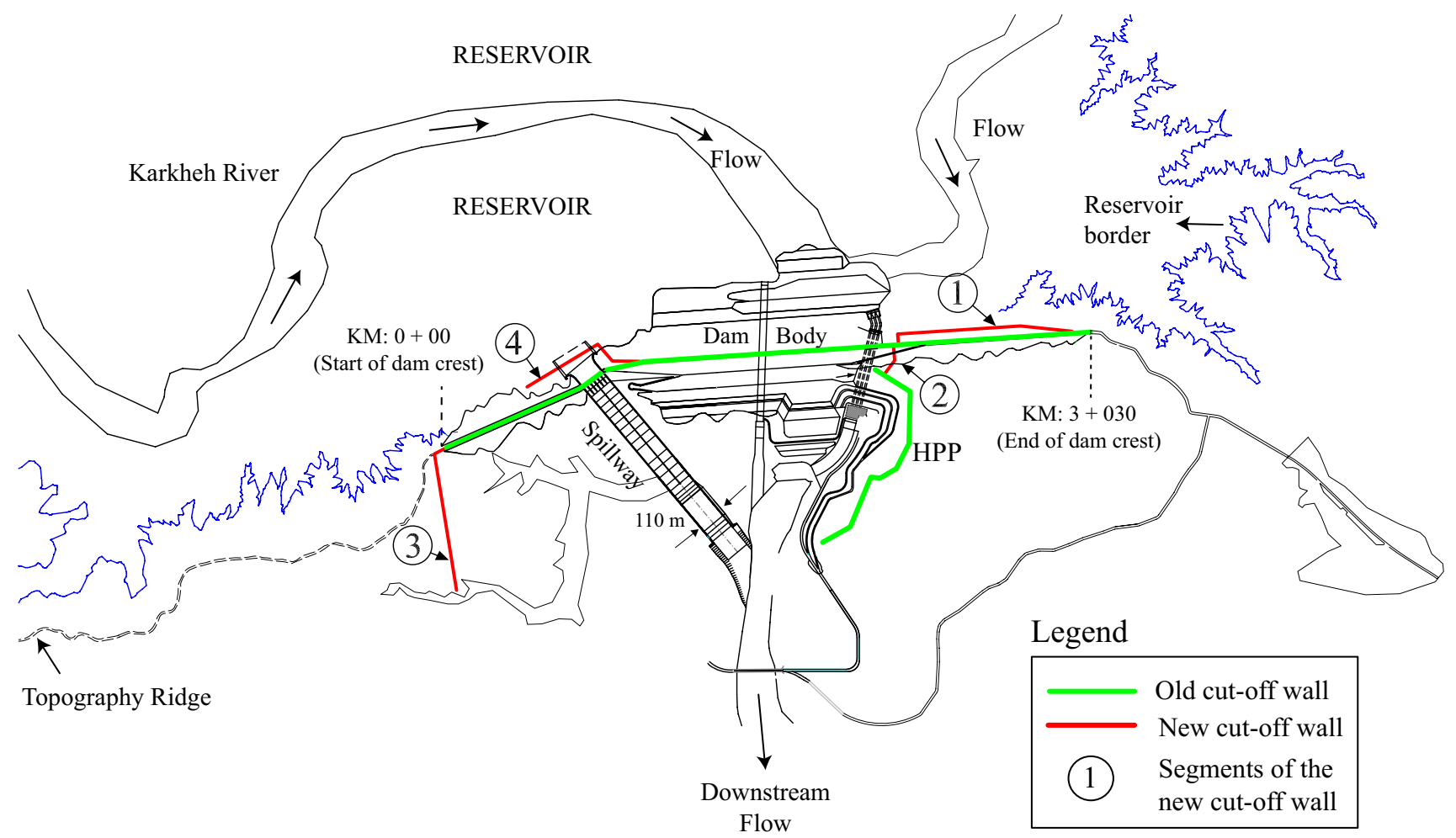

Fig. 1 General plan of the Karkheh dam and hydropower project. The old cut-off wall and the four segments of the new (complementary) Cutoff wall are shown by green and red lines, respectively. HPP stands for HydroPower Plant 


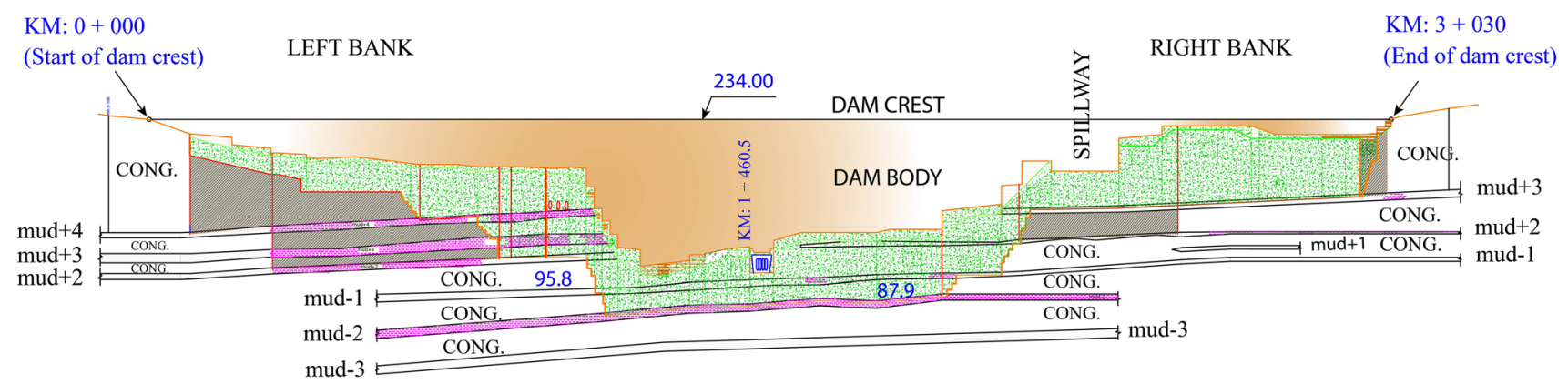

LEGEND:

CONG: Conglomerate
mud: Mudstone

Fig. 2 Karkheh dam longitudinal section showing dam geological layers. Dotted-green and hatched-black areas represent the extension of the old and new (complementary) cutoff walls. The vertical dimensions in this figure are exaggerated

enough to provide different strata for each conglomerate layer confined by the mudstone layers $[9,12]$.

The first choice for water sealing of the foundation was a grout curtain. In study phase of the Karkheh project, a series of in situ tests were conducted to study the effectiveness of a grout curtain [9]. Comprehensive cement-based grouting tests, including single-row (i.e., linear pattern) and multi-row test holes were carried out. The results of these tests showed that even using super-fine cement with a Blaine value of about $8000 \mathrm{~cm}^{2} / \mathrm{g}$, a continuous grout curtain as an anti-seepage measure could not be achieved. Only grouting of highly permeable zones (open framework gravel) could be done satisfactorily. As a result, a plastic concrete cutoff wall was considered as the main measure for the water tightening of the foundation. Karkheh dam's plastic concrete cutoff wall has a thickness of 80 to $100 \mathrm{~cm}$ constructed throughout the dam axis (thick-green lines in Fig. 1, green dots in Fig. 2) [9]. In addition to the dam main cutoff wall, another cutoff wall was constructed around the HPP (thick-green lines in Fig. 1).

Impounding of the dam reservoir in 2001 and consequent achievement of the high water level of 210.5 masl, compared to the reservoir normal water level of 220 masl, was associated with excessive seepage through the dam's foundation and abutments as well as high hydraulic gradient of around 0.2 [10]. As a result, it was decided to extend the cut-off wall system of the dam by adding four new segments at various parts of the dam (thick-red line segments 1-4 in Fig. 1).The main goal for construction of the complementary wall was to decrease the hydraulic gradient of seepage through the foundation. The construction of these new (complementary) cut-off wall segments was a challenging engineering experience because they were constructed through the dam body and the trenching was extended to the extreme depth of $115 \mathrm{~m}$. In this article, we discuss the project background information and the necessity for the construction of the new (complementary) cut-off wall and then present the technical experiences obtained through this unique process. Finally, we discuss the performance of the complementary cut-off wall in seepage control.

\section{Literature review and innovation of this research}

Plastic concrete cut-off walls as the water sealing element of dam foundations have been the subject of several studies. Yuzhen et al. [1] studied the mechanical properties of the plastic concrete and found that the plastic-shearing is the dominant failure mode under confining pressure. Hinchberger et al. [2] investigated the mechanical and hydraulic characterization of plastic concrete. Construction of a plastic concrete wall for the Island Copper Mine was reported by Davidson et al. [13] who successfully developed the wall into a challenging soil condition including excavation through a loose, porous rock-waste dump and implanting the wall toe into a hard glacial sediment. Xiong et al. [14] performed stress deformation analysis for plastic concrete walls. A review of the literature reveals that few studies are available worldwide on the mechanical properties of plastic concrete cut-off walls; hence more research and case studies are necessary to develop knowledge/experience on this topic. In this context, this research is unique as we present a complicated engineering case study on the construction of plastic concrete cut-off walls.

\section{The necessity for a complementary cut-off wall}

By increasing the reservoir water elevation to the elevation 210.50 masl in March 2004, which was $9.5 \mathrm{~m}$ below the dam's normal water level of 220 masl, excessive seepage 
was observed through the dam foundation and abutments (Fig. 3). Figure 3 shows that the total seepage volumes through the left and right banks of the dam were 2700 and $1900 \mathrm{Lit} / \mathrm{S}$, respectively, at the maximum water level of 210.5 masl. The high hydraulic gradient values were also a significant concern as they were around 0.2 at some parts of the dam. Such unexpected excessive water seepage was attributed mostly to the inaccurate estimate of the dam foundation permeability coefficient [8].

A series of remedial measures were implemented to increase the safety factor of the dam, including extension of the cut-off wall both at the right and left abutments, filling of different valleys around the dam abutments [11], installation of new relief wells at the dam toe [7], and grouting of dam foundation through access galleries [3, 4]. A core purpose for these remedial measures was to decrease the hydraulic gradients of the seepage flows. The most important feature of these measures was the extension of the existing cut-off wall at the left and right banks. Four complementary cut-off walls were constructed and were connected to the main (old) cut-off wall which are:

- Extension of the left bank cut-off wall from station $0+851$ to $0+100$ (complementary cut-off wall segment-1 in Fig. 1): This cut-off is attached to the mud layer $(+2)$ from station $0+850$ to station $0+300$ and to the mud layer $(+4)$ from station $0+300$ to $0+100$ (Figs. 1, 2).

- Connection of the HPP cut-off wall to the dam's main cut-off wall (complementary cut-off wall segment- 2 in

(a) Left bank

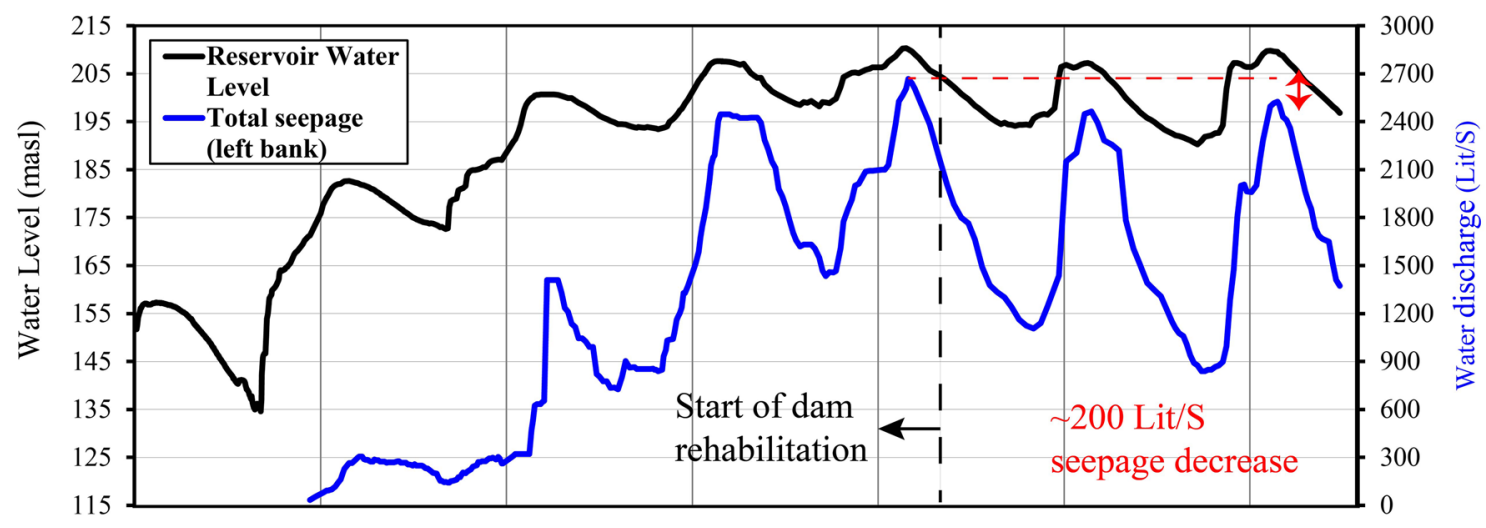

(b) Right bank

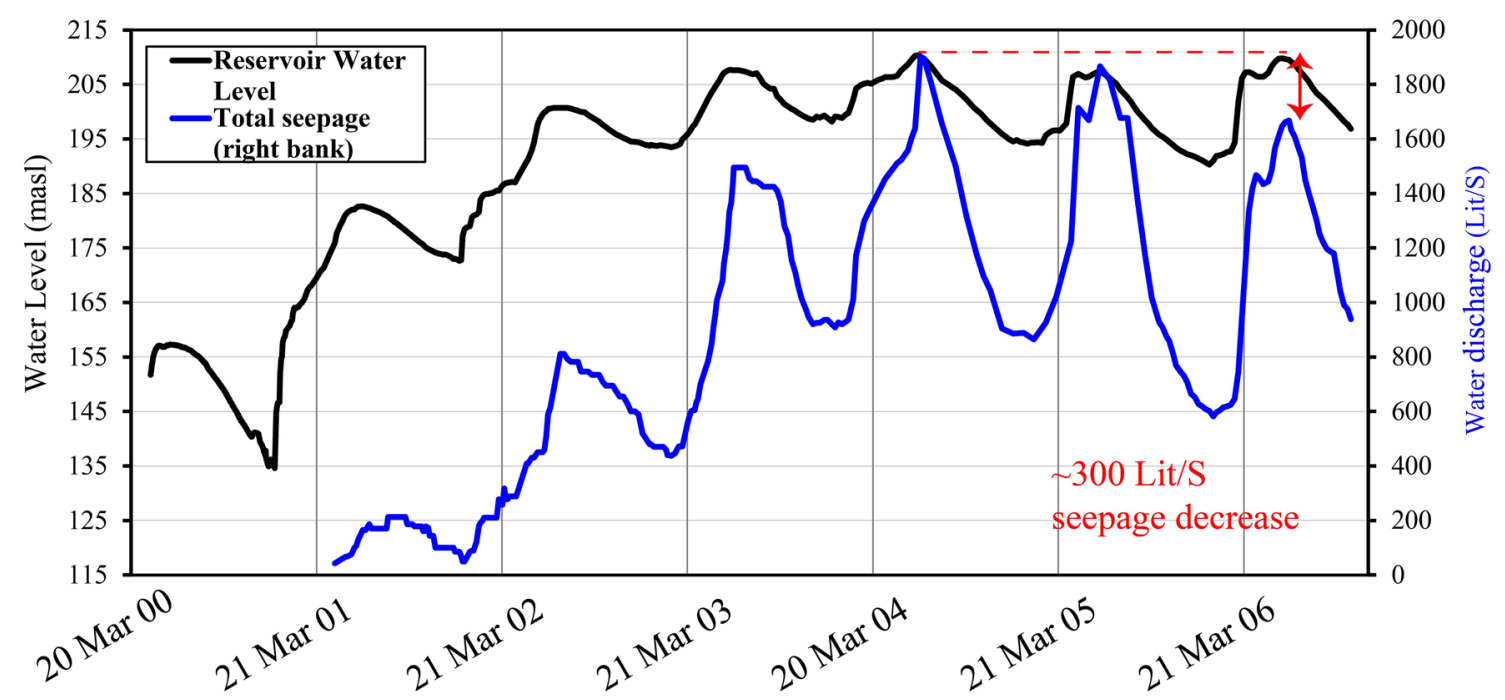

Fig. 3 Seepage through the Karkheh dam's left and right banks. The start time of the dam rehabilitation and the effect of remedial works on seepage control are shown in this figure 
Fig. 1): Analyses showed that at the reservoir's normal water level, the seepage at the powerhouse is expected to be around a high value of $90 \mathrm{Lit} / \mathrm{S}$ [16]. This is mainly because of a gap between the dam's main (old) cut-off wall and the HPP cut-off wall (Fig. 1); therefore, it was decided to close this gap.

- Extension of the cut-off wall at the right bank above mud (+3) (complementary cut-off wall segment-3 in Fig. 1): The 3D seepage analysis, performed by the FEFLOW model (Finite Element subsurface FLOW system: https ://www.mikepoweredbydhi.com/products/feflow) [17], revealed that the hydraulic gradient at the right bank of the dam is expected to be about 0.2 which was significantly more than the acceptable limit of 0.075 [16]. The goal of this cut-off wall was to reduce the hydraulic gradient at this part of the dam foundation.

- Cut-off wall at the right bank between mud $(+2)$ and mud $(+3)$ around spillway (Figs. 1, 2) (complementary cut-off wall segment-4 in Fig. 1): The spillway structure was in direct contact with the reservoir water through conglomerate layer between mud $(+2)$ and $(+3)$. Hence, at high reservoirs levels, the uplift pressure beneath the spillway structure was expected to become high. This new cut-off wall protects the spillway.

\section{Equipment}

The complementary cut-off wall segments 1 and 4 were placed at the upstream of the dam body (Fig. 1, thick-red lines) for two reasons: first, trenching through the dam's core could be unsafe because its pore pressure was relatively high even after several years of impounding; and second, the technical limitations of cut-off wall trenching at large depths of $>100 \mathrm{~m}$. For the connection region, where the new cut-off wall is connected to the old wall, trenching at depths of up to $115 \mathrm{~m}$ was inevitable because the connecting panel had to be executed from the dam crest. The existing trench-cutting machine at the Karkheh dam site (BAUER BC-30) was able to execute the wall up to $80 \mathrm{~m}$ in depth. Therefore, a new trench-cutting machine, BAUER BC-40 (Fig. 4) (http:// www.bauerpileco.com/en/products/diaphragm_wall_techn ology/trench_cutter_systems/), having the capability to work at depths up to $120 \mathrm{~m}$, was supplied for the project.
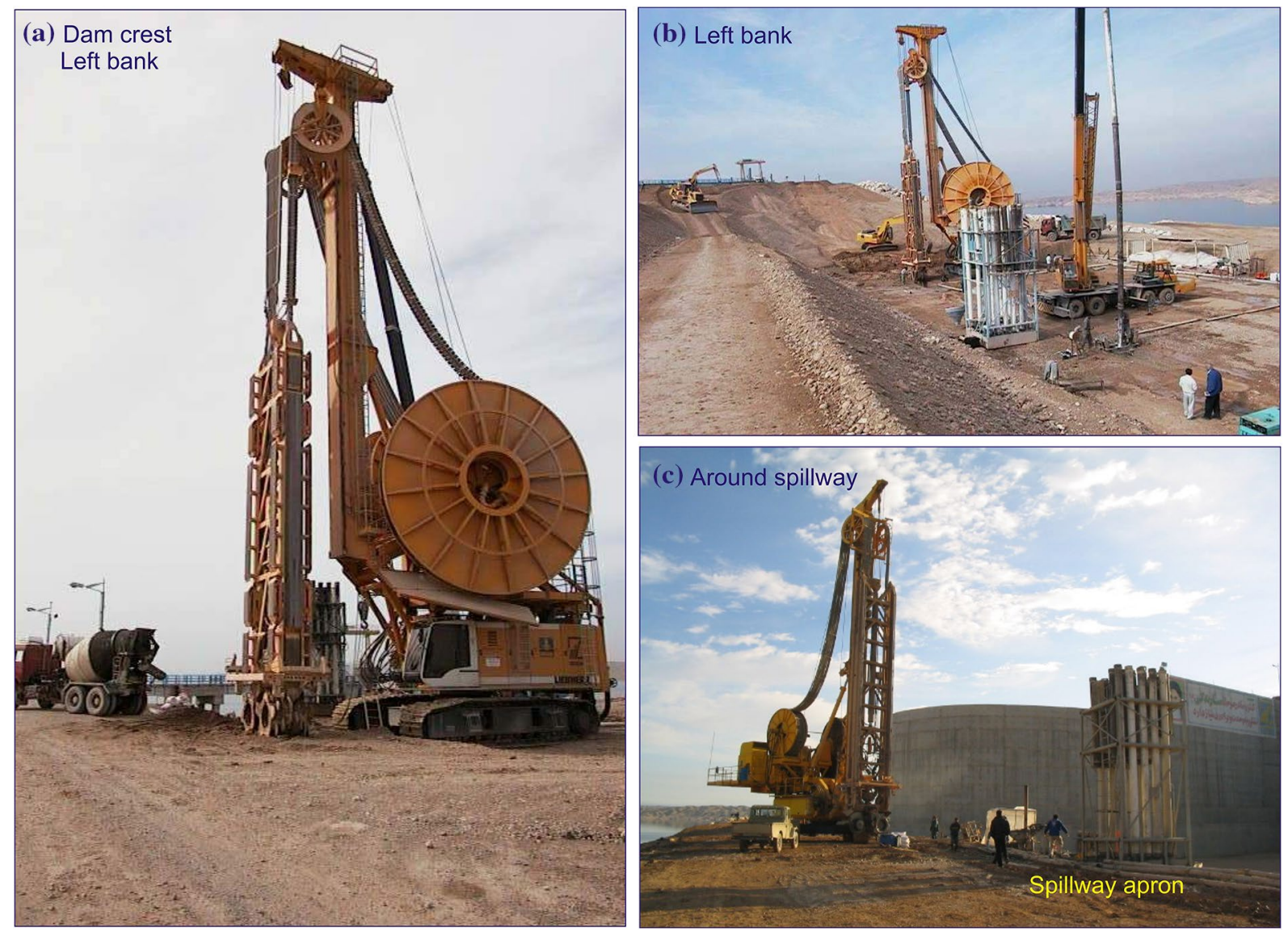

Fig. 4 The BC-40 trench-cutter working at various part of the Karkheh dam during the construction of the complementary cutoff wall 


\section{Technical challenges for the construction of the complementary cut-off wall and the innovative engineering solutions}

The construction of the Karkheh dam complementary cutoff wall was associated with many technical challenges which required innovative engineering solutions and equipment. Main challenges were:

- Connection between the new and old cut-off walls and construction of the connecting panel between the old and new cut-off walls,

- Trenching and placement of plastic concrete wall through relatively course materials including drain and filter,

- Slurry loss during trenching through dam body zones.

In the following, each of these challenges and the employed innovative solutions are presented.

\subsection{Connection between the new and old cut-off walls}

The new cut-off wall was designed to be connected to the old wall at three locations of A, B and C (Fig. 5) which consists of two locations at the left bank (points A and B) and the other location at the right bank (Point C). Piezometers installed at two opposite sides of the old cut-off wall indicated that the water head difference between the two opposite sides of the old cut-off wall ranged between 20 and 50 meters, depending to the reservoir water level. In other words, at the connection locations A, B, and C (Fig. 5), there is a $20-50 \mathrm{~m}$ water head difference between two opposite sides of the main cut-off wall. This indicates that any potential rupture/crack in the wall, due to new cut-off wall construction, could have serious consequences for the dam's safety. We note that the amount of excavation deviation from the vertical position may increase at larger depths of up to $115 \mathrm{~m}$ during the trench-cutting process by the $\mathrm{BC}-40$. Although the trenching deviation has been estimated to be within a few centimeters by the BC- 40 manufacturer, it was essential to consider additional safety measures because such deep trenching $(>100 \mathrm{~m}$ ) was not reported worldwide before the Karkheh project. We designed the following two measures:

a. During the construction of the complementary cut-off wall, the reservoir water level was kept at low elevations to maintain a relatively low water pressure difference between the two opposite sides of the old cut-off wall.

b. To approach the old cut-off wall, a U-shaped paneling pattern was designed (Fig. 6). The U-shaped pattern is consisting of six panels: three panels perpendicular to the old cut-off wall's axis and the others parallel to it. The purpose of this U-shaped pattern was to provide an area of balanced hydrostatic water head at depth for construction of the connecting panel (i.e., panel No. 6 in Fig. 6). In this method, at first the panels No. 1 and 2 were constructed parallel to the old cut-off wall. Then, panels No. 3 and 4 were made in normal direction to the old wall's axis. After performing panel No. 5, the connecting panel (i.e., panel No. 6) was constructed with $20 \mathrm{~cm}$ overlap with the old wall. It was believed that by performing panels No. 1 to 5, the hydrostatic pressure inside the U-shaped space would have been significantly decreased; hence, providing a safe zone for making the connecting panel. The advantages of the U-shaped pattern over a line pattern lie in the facts that it significantly
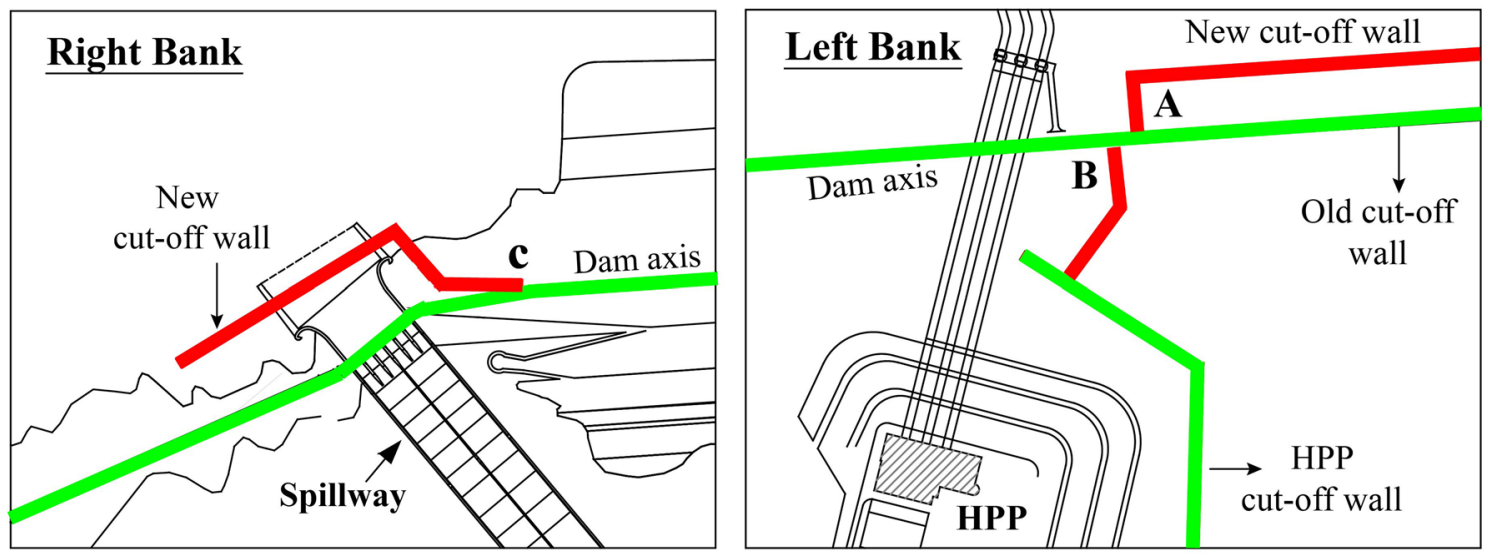

Fig. 5 Three locations for connection of the new cut-off wall to the old wall at the left and right banks of the dam (locations A, B and C) 
Fig. 6 The U-shaped paneling pattern to connect the new cutoff wall to the old wall as well as the supporting panels (SP) (cyan-colored panels) at both sides of the new cut-off wall panels (blue-colored panels). Dimensions are in meters

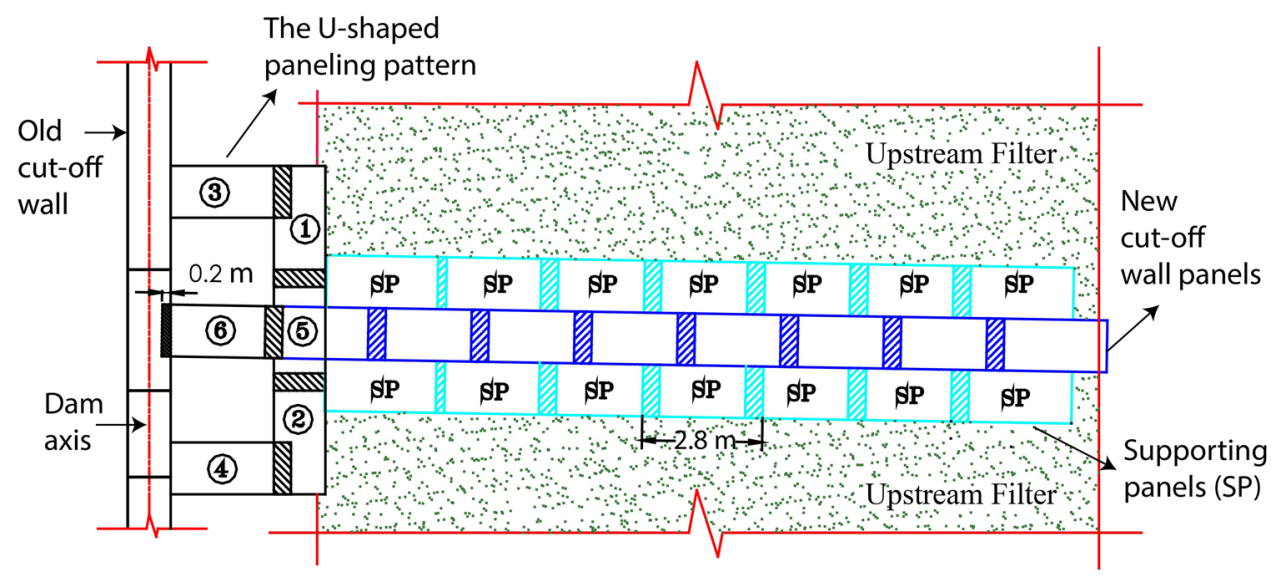

decreases the hydrostatic pressure on the final connecting panel (i.e., panel No. 6) as well as it offers additional safety to the system in case the final connecting panel fails for whatever reason.

The panel No.6 plays a key role in our U-shaped pattern. Because the construction of this panel requires cutting some part of the old cut-off wall, a meticulous procedure was necessary for its construction. In this context, the excavation rate for the panel No. 6 was reduced. The drilling fluid used for excavation of the connecting panel was heavier than ordinary drilling fluids to prevent possible slurry loss, which could have negative consequences. In addition, the mechanical properties of the plastic concrete were carefully monitored during construction of the panel No. 6 to ensure the high quality of the materials.

\subsection{Trenching and placement of plastic concrete wall through filter material}

The other technical challenge was associated with the trenching through various dam zones, in particular highly permeable filter and drain materials. Following the completion of the U-shaped panels, eight panels of the new left bank cut-off wall cross the upstream filter zone of the dam body (Fig. 6). Since filter is composed of relatively permeable and un-cemented materials, the excavated walls of the trenches could slide into the panel during trench-cutting by the BC-40. To resolve this problem, we considered two solutions during the design phase: grouting of the filter zone before trenching or construction of supporting panels (SPs in Fig. 6). Finally, the latter solution was chosen. In this order, seven supporting panels were constructed in each side of the main panels (SPs in Figs. 6, 7). Supporting panels acts as retaining walls and prevent filter materials from sliding into the excavated area (Figs. 6, 7). Supporting panels have different depths ranging from 17 to $45 \mathrm{~m}$, based on the depth of the filter zone at each location

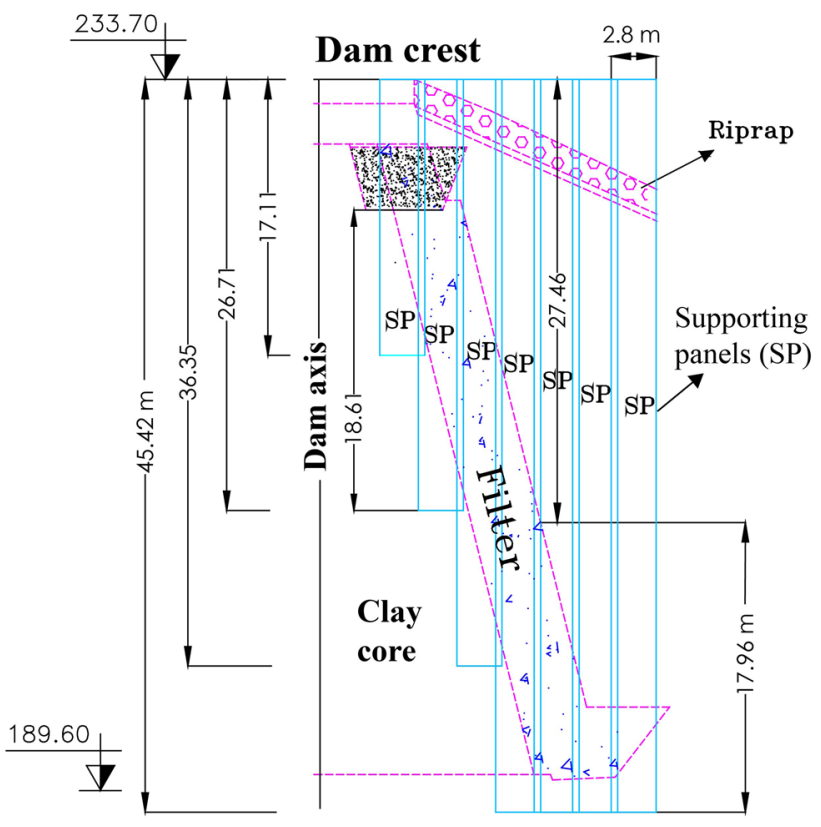

Fig. 7 A vertical section of the seven supporting panels (SP) in the filter zone of the dam body

(Fig. 7). The joints of supporting panels do not match with those of the main panels (Fig. 6).

\subsection{Slurry loss during trenching through dam body zones}

Slurry loss occurred in some cut-off wall panels, especially in the U-shaped connecting panels. Since part of the new cut-off wall was placed in the dam body, any slurry loss during the construction of the new cut-off wall would be a risk for dam safety due to the potential collapse of the excavated walls. Slurry loss may cause withdrawal of the drilling fluid levels in the excavated area, and consequently cause panel failure. Some susceptive zones for slurry loss are open 
framework gravel zones between conglomerate layers, and the contact layer between the dam body and the foundation.

At the Karkheh dam site, a mix of bentonite and water, having a density of about 1.03 to $1.05 \mathrm{gr} / \mathrm{cm}^{3}$, Marsh viscosity of about 32-37 s, and PH range of 7-9 was used as the drilling slurry. During the construction of panels Nos. 3 and 4 , slurry loss took place with the maximum loss rate of about $100 \mathrm{~cm} / \mathrm{min}$. To stop slurry loss and to find an optimum and efficient measure, three different methods were considered as follows:

- Application of more viscous drilling slurry for excavation,

- Adding filling materials such as a combination of clay and sand to the excavated zones,

- Adding a grout mix containing cement, water, and bentonite to the excavated zones.

The above measures were applied to stop slurry loss at panel No. 4 (Fig. 6). Results showed that the third measure, i.e., application of a grout mix, was the most effective one. To stop the slurry loss in the panel No. 4 , at first a relatively viscose drilling fluid, having density of about $1.14 \mathrm{~g} / \mathrm{cm}^{3}$, and Marsh viscosity of about $37 \mathrm{~s}$ was used which was not successful. Then, as a second try, we added materials such as a combination of clay and sand to the panel. This method showed satisfactory results at the beginning and was capable of reducing the rate of slurry loss from 100 to $10 \mathrm{~cm} / \mathrm{min}$. However, gradually the slurry loss rate increased again and reached the high rate of $126 \mathrm{~cm} / \mathrm{min}$ proving that the second method also was not efficient in slurry loss control. Finally, the method of adding a grout mix to the panel was examined. We designed a cement-based grout mix whose components were: $150 \mathrm{~kg}$ of cement and $160 \mathrm{~kg}$ of bentonite and water was used. Such a grout mix stopped the slurry loss completely. Grouting was performed using a diesel pump providing pressure of around 5 bar which guided grouting materials into the grouting holes spaced 1-2 $\mathrm{m}$ from each other.

\section{Effectiveness of the complementary cut-off wall in seepage control}

The new cut-off wall was successful in reducing the seepage and hydraulic gradient as outlined in the following for each segment of the new wall individually:

- The new cut-off wall in the left bank and around the HPP (complementary cut-off wall segments 1 and 2): after the execution of right bank connection at the station

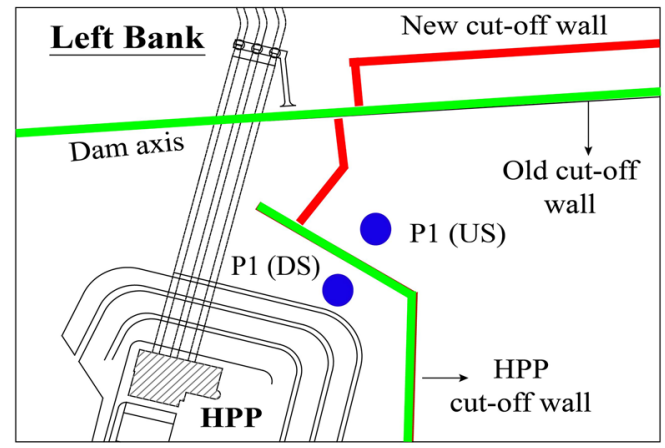

Piezomete

DS: Downstream

US: Upstream

(a) Effect of the new wall on the peizometric water level

(b) Effect on the seepage control
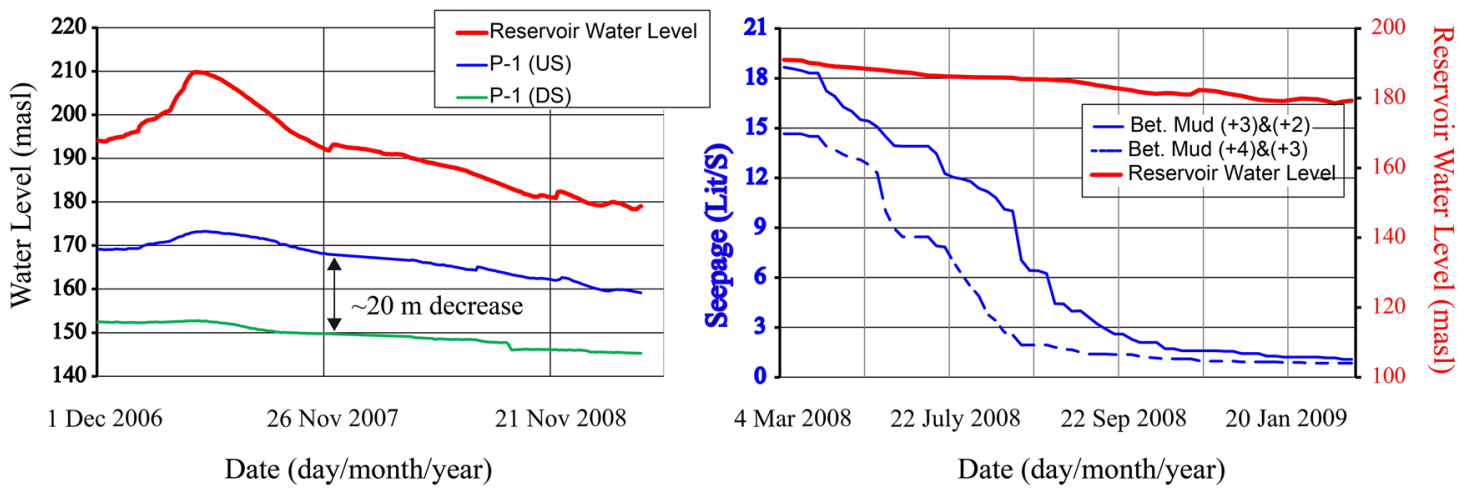

Fig. 8 Effects of the construction of the new cut-off wall segments 1 (left bank) and 2 (around HPP) on the seepage control 
$0+850,10 \mathrm{~m}$ water elevation reduction was observed at the piezometers installed downstream of the new cut-off wall, between mud $(+2)$ and mud $(+3)$. Additionally, the hydraulic gradient was reduced from 0.154 to 0.13 between mud $(+2)$ and mud $(+4)$. The total water seepage was reduced around $200 \mathrm{Lit} / \mathrm{S}$ (Fig. 3). The piezometers installed at the opposite side of the HPP wall, P1 (US) and P1 (DS) in Fig. 8a, showed $20 \mathrm{~m}$ of water level decrease after the construction of new cat-off wall 3. Figure $8 \mathrm{~b}$ reveals a significant decrease in water seepage through the left bank following the construction of this new wall (segments 1 and 2).

- The new cut-off wall in the right bank (complementary cut-off wall segment-3): After the construction of around half of this wall, the seepage amount at the right bank is reduced about $25 \%$ (300 Lit/S, Fig. 3), and the hydraulic gradient was reduced from 0.2 to 0.095 . Figure 9 shows that the piezometers installed at the downstream of the complementary wall, P2 (DS) and P3 (DS) in Fig. 9, have flat water levels which indicate these observation wells receive no seepage from the dam's reservoir. In other words, the downstream side of the wall is almost dry.

- The new cut-off wall around spillway (complementary cut-off wall segment-4): Data from piezometers installed at both sides of the new cut-off wall around spillway, P4 and P5 in Fig. 10, showed water levels decreased between $18-22 \mathrm{~m}$ as a result of the new wall construction.
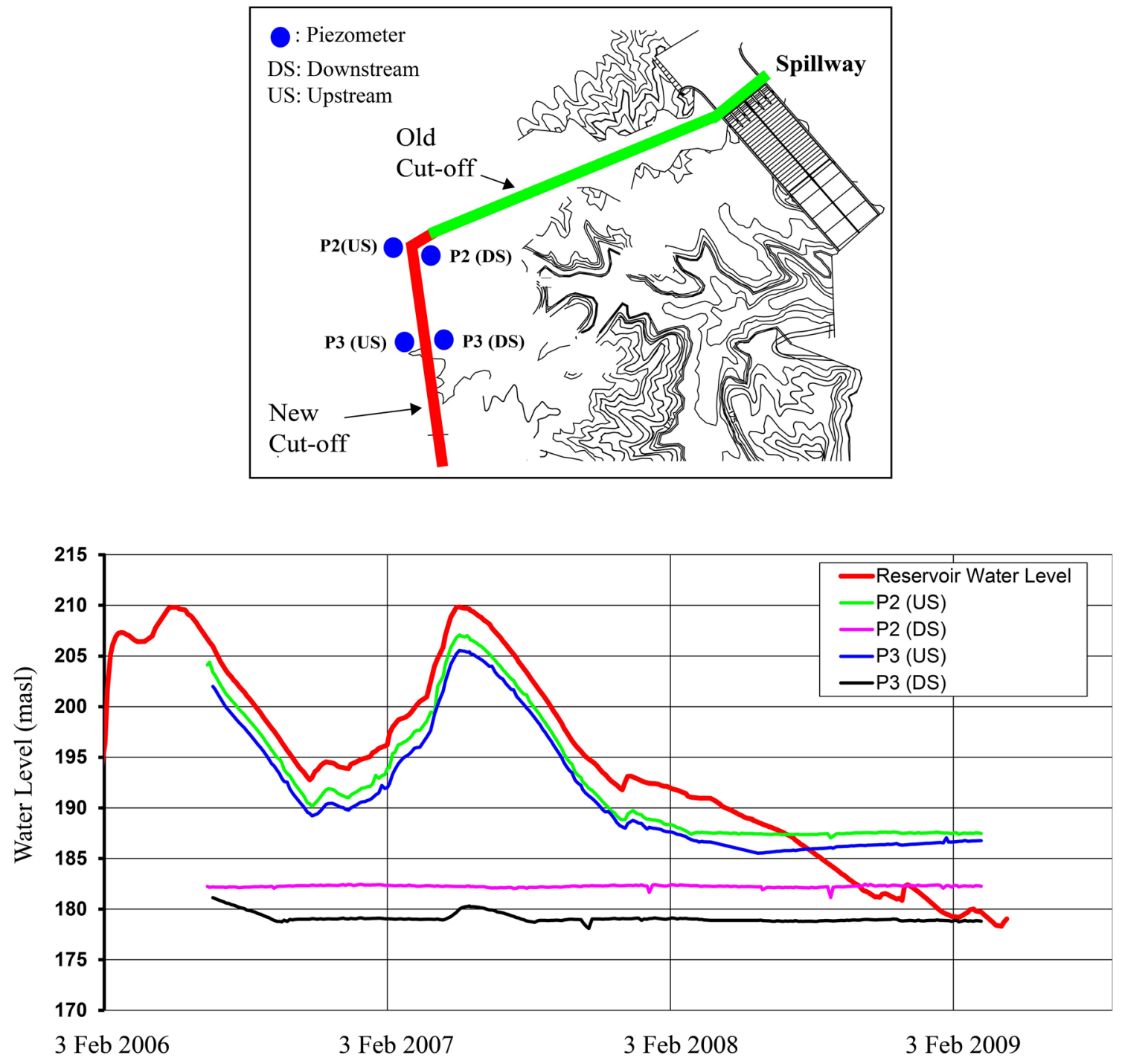

Date (day/month/year)

Fig. 9 Effects of the construction of the new cut-off wall segments 3 (right bank) on the seepage control 


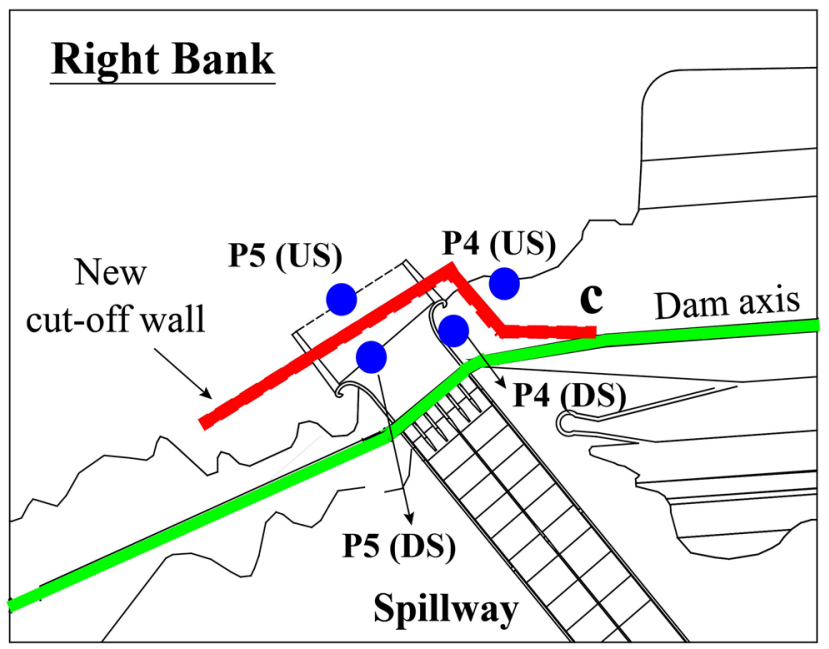

: Piezometer

DS: Downstream

US: Upstream

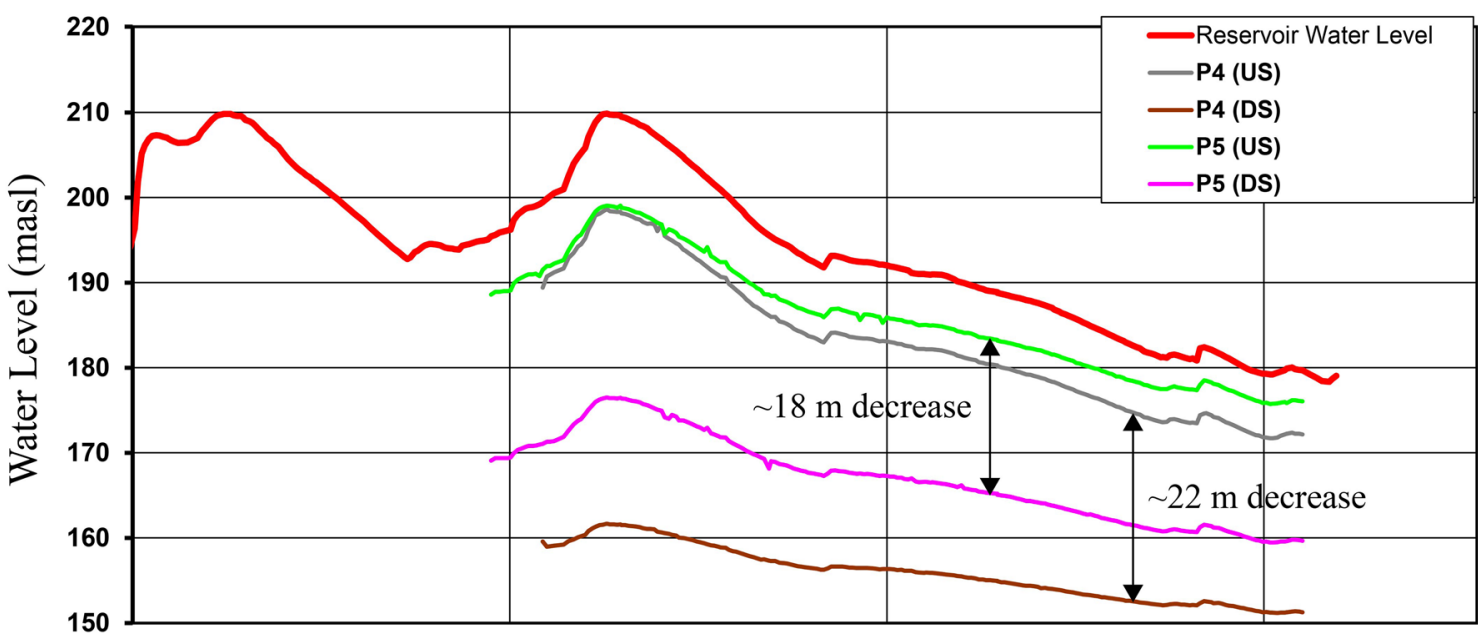

2 Feb $2006 \quad 2$ Feb $2007 \quad 2$ Feb $2008 \quad 2$ Feb 2009

Fig. 10 Effects of the construction of the new cut-off wall segments 4 (around the spillway) on the seepage control

\section{Conclusion}

Since water seepage from Karkheh dam foundation and abutments were higher than expectation, it was necessary to take remedial measures. The construction of a complementary cut-off wall was the central part of these remedial measures which was associated with a number of technical challenges such as connection between the new and old cutoff walls; trenching and placement of plastic concrete wall through relatively course materials like filter; and slurry loss. For connecting the new cut-off to the old one, a U-shaped paneling pattern was employed. This pattern decreased the hydrostatic pressure between the two opposite sides of the old wall. To decrease the risk of trenching through the filter zone of the dam, supporting panels were used. Supporting panels act as retaining walls and prevents filter materials from sliding into the excavated area. For stopping slurry loss during excavation, different methods were exploited, among which the most efficient method was adding of cement-based grout mix to the excavated zones. Instrumentation data from piezometers installed at opposite sides of the new cut-off walls revealed that water levels decreased $\sim 20 \mathrm{~m}$ as a result of the construction of the new cut-off walls. In addition, total seepage and the hydraulic gradient at various parts of the dam were reduced; for instance, in the right abutment, total seepage was cut for $25 \%$ and the hydraulic gradient was reduced from 0.2 to 0.095 .

Acknowledgements The authors would like to acknowledge the Iran Water and Power Resources Development Company, IWPC, the client of the Karkheh dam/reservoir project, the contractor of the project and many colleagues at the MGCEC who assisted us in the design and construction of this mega infrastructure. Authors declare that they have no competing interests regarding the work presented in this article. 
Open Access This article is distributed under the terms of the Creative Commons Attribution 4.0 International License (http://creativeco mmons.org/licenses/by/4.0/), which permits unrestricted use, distribution, and reproduction in any medium, provided you give appropriate credit to the original author(s) and the source, provide a link to the Creative Commons license, and indicate if changes were made.

\section{References}

1. Yuzhen Y, Jialin P, Fengde L (1995) Study on mechanical properties of plastic concrete for cut off wall. J Hydraulic Eng 8:56

2. Hinchberger S, Weck J, Newson T (2010) Mechanical and hydraulic characterization of plastic concrete for seepage cut-off walls. Can Geotechnical J 47(4):461-471

3. Heidarzadeh M, Mirghasemi A, Eslamian F, Sadr-Lahijani S (2013) Application of cement grouting for stabilization of coarse materials. Intl J Civil Eng 11(1):71-77

4. Heidarzadeh M, Mirghasemi AA, Etemadzadeh SM (2007) Experimental study of chemical grouting of conglomerate foundations. Intl J Civil Eng 5(1):66-83

5. D’Appolonia DJ (1980) Soil-bentonite slurry trench cutoffs. J Geotech Geoenviron Eng 106:399-417

6. Mirghasemi Ali A, Pakzad M, Shadravan B (2005) The world's largest cutoff wall at Karkheh dam. Int J Hydropower Dams 2:90-94

7. Heidarzadeh M, Mirghasemi AA, Niroomand H (2015) Construction of relief wells under artesian flow conditions at dam toes: engineering experiences from Karkheh dam, Iran. Intl J Civil Eng 13(1):73-80

8. Mirghasemi AA, Pakzad M (2005) Uncertainty in Karkheh dam foundation permeability. In: Proceedings of the 73rd annual meeting of international commission On Large Dams (ICOLD), May 1-6, 2005, Tehran, Iran

9. MahabGhodss Consulting Engineers (1998) Kharkheh project technical report of dam body and foundation, 138 pages, Tehran, September 1998, Iran

10. Mirghasemi AA, Tarkeshdooz N, Daadgostarnia S (2000) Pore pressure monitoring within the foundation and impervious zone of Karkheh Dam during construction. In: Proceedings of 20th international congress on large Dam, ICOLD, III, 259-247, Beijing, Volume

11. Mirghasemi AA, Pakzad M, Tarkeshdooz N (2004) Rehabilitation of Karkheh Dam foundation after four years of impounding. In: Proc. of 72nd ICOLD Annual Meeting, Seoul, South Korea

12. Heidarzadeh M, Mirghasemi AA, Eslamian F, Niroomand F, Etemad Zadeh SM (2006) Construction of pressure relief wells under flowing artesian conditions, Karkheh Storage Dam-Iran. In: 74th annual meeting of ICOLD, May 2006, Barcelona, Spain

13. Davidson RR, Denise G, Findlay B, Robertson RB (1992) Design and construction of a plastic concrete cutoff wall for the Island Copper Mine. In: Slurry Walls: design, construction, and quality control. ASTM International

14. Xiong H, Wang Q, Gao X, Zhou W, Gao M (2010) Stress deformation analysis of plastic concrete cutoff wall for the first stage cofferdam of Shawan hydropower station. J Hydroelectric Eng 2:035

15. Mirghasemi AA, Pakzad M, Tarkeshdooz N (2004) Rehabilitation of Karkheh dam foundation after four years of impounding. In: Proceedings, 72nd ICOLD annual meeting, Seoul, South Korea

16. Iran Water and Power Resources Development Company (2004) Technical meeting memorandum in Germany, 1-5 November 2004. Munich, Germany

17. MahabGhodss Consulting Engineers (2004) 3D Seepage analysis of the Karkheh dam, 213 pages, Tehran, December 2003, Iran 